\title{
Design, poesia e vida: Memória e pertencimento na cidade de Belo Horizonte
}

Paula Márcia Alves Quinaud Minchilo;

Lorrayne Celine Frade Bissoli

resumo:

Belo Horizonte é uma cidade historicamente cultural, com vida noturna ativa, muitos bares e encontros e poetas que registravam sua essência em livros e jornais. A cidade é poeta desde que nasceu. Seus cenários - natural, urbano e político - sempre foram alvo de olhares sensíveis e, ao mesmo tempo, críticos. $O$ objetivo deste trabalho foi discutir as relações entre o design, poesia e a cidade, abordando o pertencimento como peça chave. A história, a memória e a relação de Belo Horizonte com a poesia foram estudadas através do olhar interdisciplinar do design. O público da cidade, diverso, usa à sua maneira o espaço urbano, grande palco de memórias, que o design se encarrega de resgatar e compreender. Nesse novo contexto atual, onde conceitos arraigados precisam ser revistos, pensar caminhos possíveis para a arte também é respirar. A metodologia utilizada foi a pesquisa bibliográfica, além da observação direta do objeto de estudo - a cidade.

palavras-chave:

Belo Horizonte; design; memória; pertencimento; poesia 


\section{$1 \mathrm{BH}$, poesia e design}

Ao andar pelas ruas de Belo Horizonte é possível perceber inúmeros edifícios de outras épocas. Em bairros tradicionais como o Centro, Santa Tereza, Santa Efigênia, Funcionários e Floresta, a maioria das fachadas é nitidamente histórica e muitas são tombadas. Esses bairros, casas, cenários de encontros, reuniões, bate-papos por vezes religiosamente repetidos, marcaram a vida e a memória do povo belo-horizontino. Um exemplo conhecido é o Clube da Esquina, um grupo de encontros musicais que nasceu da amizade entre Milton Nascimento e os irmãos Borges (Marilton, Márcio e Lô) no bairro Santa Tereza, no encontro das ruas Divinópolis e Paraisópolis. Como esse, diversos espaços também remontam historicamente à poesia, como o famoso Café Nice, palco de histórias desde 1939.

$\mathrm{BH}$, Belô, Belo Horizonte, conforme o grau de intimidade ou afeto, sempre foi conhecida por sua vida boêmia. Os atos de encontrar os amigos em um bar para conversar e beber cerveja, ou tomar café no meio da tarde, por exemplo, são episódios singelos, porém extremamente semânticos, e muito característicos da cultura local de uma cidade cheia de vida. Nesse contexto, é preciso buscar o olhar do design, enquanto um modo de transmissão de ideias e conceitos a partir de processos, elementos e princípios. O que se propõe aqui é perceber a forma em que a conformação do espaço público ou privado, quase sempre alinhada às premissas, estratégias e significados atribuídos pelo design de ambientes, impacta diretamente nessas vivências poéticas urbanas de maneira individual ou conjunta. Essa perspectiva da experiência em lugares de coletividade diz respeito ao pertencimento, exclusão e à própria cidadania. Para compreender a medida em que esses universos se entrelaçam, é necessário que se pontue o entendimento de cada um deles. A análise se dá a partir de pesquisa bibliográfica e em um campo/cidade ainda transitável, num momento de encontros descomplicados e reuniões possíveis. Hoje, todo esse novo panorama dos últimos meses, provoca novas reflexões e inquietações sobre caminhos possíveis em um mundo que pede mais do que nunca as contribuições do bom design, da arte e da poesia.

\subsection{Belo Horizonte início do século XX}

A mudança da capital de Minas Gerais, de Ouro Preto para o Curral Del Rei, provocou rebuliços. A sua escolha se deu pelo contexto político econômico do estado à época: a decadência de Ouro Preto, economicamente estagnada devido ao esgotamento da exploração do ouro e diamantes, e, contrário a isso, a Região Sul e Zona da Mata com crescimento exponencial nos quesitos econômicos e populacionais. O Congresso Mineiro, em 1893, em Barbacena, designou Curral del Rei como a nova capital de Minas Gerais (RESENDE, 1974, p.601; apud SANTOS; FIALHO 2016, p. 775,776).

Logo após a seção decidir sobre a transferência da capital, em 1894 foi nomeada a "Comissão Construtora da Nova Capital" (CNCC), encarregada de realizar os levantamentos geodésico e topográfico. A comissão foi liderada, inicialmente, por Aarão Leal de Carvalho Reis (1847-1919) responsável pelo projeto da capital, planificação e concretização do plano. O projeto foi executado entre os anos 1894 e 1897, seria a primeira cidade planejada do Brasil, e as influências europeias no projeto originaram uma cidade com uma malha urbana regular e geométrica. Como pontua Carmona (2015), a cidade tornou-se símbolo da modernidade, da beleza e da higiene, e para isso foi completamente transformada. "Casas, choupanas, comércio e igrejas destruídas, sob a argumentação de que suas formas e traçados eram incompatíveis com o projeto modernizador idealizado pelos engenheiros responsáveis pela construção da nova capital" (CARMONA, 2015, p. 20).

A cidade foi dividida em zonas: Zona Urbana; Zona Suburbana; Zona Agrícola. A primeira era delimitada pela Avenida do Contorno; a segunda destinada à expansão urbana; e a terceira era responsável pelo abastecimento da cidade. "Essa divisão funcional das áreas traz também uma divisão das atividades comerciais, culturais, políticas, habitacionais e de lazer de forma bem rígida no espaço." (LEMOS et al 2019, p. 23). O engenheiro Aarão Reis descreve o projeto para uma revista sobre os trabalhos da Comissão Construtora, onde expressa certa preocupação com a população enquanto usuária do projeto:

Às ruas fiz dar a largura de 20 metros, necessária para a conveniente arborização, a livre circulação dos veículos, o tráfego dos carros e trabalhos da collocação e reparações das canalizações subterrâneas. Às avenidas fixei a largura de $35 \mathrm{~m}$, 
sufficiente para dar-lhes a belezza e o conforto que deverão, de futuro, proporcionar à população. (REIS, 1895).

Dentro dos limites da Zona Urbana, eram seguidos princípios higienistas para que assim a cidade conquistasse ainda mais o ar europeu. Além disso, a própria $\mathrm{CNCC}$ era responsável pela homogeneização de aspectos funcionais e estéticos de construções públicas e privadas da cidade. "Essa padronização foi tanta que se criou a ideia de casas-tipo que se multiplicavam na paisagem da nova capital,e se estendeu as regras para os interiores das residências" (LEMOS, 1988, apud LEMOS et al, 2019). Existiam seis categorias de casas-tipo, todas com elementos ecléticos, e com a relação entre número de janelas e grau de ornamentação de fachadas com a posição social dos donos.

FIGURA 1 - Praça Sete de Setembro - Belo Horizonte 1940

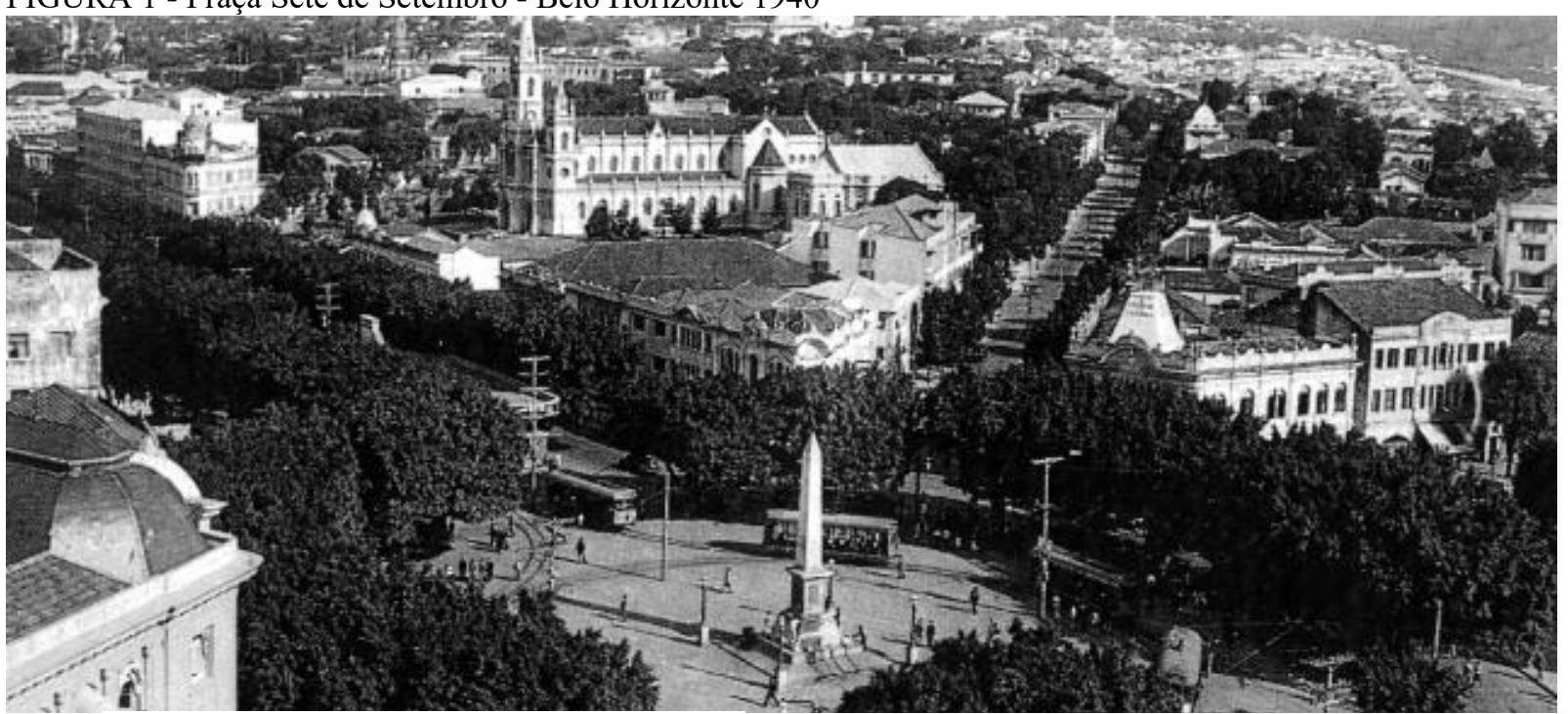

Fonte: Arquivo Público da Cidade De Belo Horizonte, 2017

$\mathrm{O}$ estilo arquitetônico predominante foi o ecletismo, como se percebe na figura 1, adotado em edificações públicas, comerciais e privadas. $\mathrm{O}$ alinhamento do estilo à modernidade proposta pela CNCC foi a principal razão pela qual o ecletismo foi empregado. Lemos (1988) descreve algumas das características empregadas:

[...] construções alinhadas às ruas e junto aos passeios, fachadas simétricas, frontões, cimalhas, platibandas ornamentadas, bandeiras nas portas e janelas, colunas de diversas tipologias, frisos e almofadas nas fachadas e aberturas, aberturas, molduras e esculturas que caracterizavam o proprietário, as entradas das maiorias das casas era pela lateral e havia jardins ao fundo; os telhados eram de duas águas revestidas de telhas francesas e lambrequins. (LEMOS, 1988 apud LEMOS et al, 2019, p. 29)

Com a vinda de novos habitantes abastados, houve a necessidade de se ornamentar as casas, pois as influências europeias eram tendência da época. Para isso, iniciou-se a chegada de artesãos, arquitetos, decoradores e artistas plásticos, atendendo à demanda da construção civil na cidade. Além da mão-de-obra humana, foram necessários materiais que ainda não existiam no Brasil: moldes e préfabricados para decoração, móveis, louças, cristais, vitrais, espelhos de cristal, telhas, mármores, madeiras, e manuais práticos sobre acabamentos e ornamentação (LEMOS, 2019). Assim, se teve desde os primeiros movimentos de urbanização na cidade das alterosas, o design, mesmo que sem nome ou tratados específicos, como uma premissa a pontuar escolhas e decisões. Por outro lado esse contexto de embelezamento na esfera privada, mas também na pública, trouxe desde os primeiros tempos um desenho do que poderia ser apropriável pelos fruidores locais. $\mathrm{O}$ emprego de ostentações e singularidades, com vistas à definição simbólica dos lugares de excelência, serviria também como definidor de quem poderia ou não fazer uso de um espaço que deveria ser de todos. 


\subsection{Vida literária e a cidade de Belo Horizonte}

A velocidade da construção era impressionante e vários poetas escreveram sobre um horizonte belo que mal tinha saído do papel. "A cidade é um discurso, e esse discurso é verdadeiramente uma linguagem: a cidade fala aos seus habitantes, falamos nossa cidade, a cidade em que nos encontramos, habitando-a simplesmente, percorrendo-a, olhando-a" (BARTHES, 2001, p.224). Olavo Bilac, como correspondente do A Gazeta de Notícias escreve suas primeiras impressões sobre a cidade em 1894:

Dali a meia hora, entramos na povoação. E com que surpresa e com que alegria! Supunha eu encontrar em Belo Horizonte uma ou duas dúzias de casas rústicas, num arraial quase morto, mergulhado num silêncio melancólico. Em vez disso, acho uma área povoada de mais de dois mil metros quadrados, em que levantam talvez duzentas casas - comércio animado, lavoura, curtumes, igrejas, dois hotéis, população alegre, sadia, afável, obsequiadora sem aborrecer, discreta sem matutice, e principalmente... muitas moças que nada têm de feias... (BILAC, 1894 apud CARMONA, 2015, p.40)

Machado (2009, p.81) pontua alguns autores que escreveram suas visões acerca da cidade. "Abgar Renault, João Alphonsus, Pedro Nava, Milton Campos, Ciro dos Anjos, Alberto Campos e Carlos Drummond de Andrade estão entre os que se destacaram nas páginas do jornal Diário de Minas, com publicações que traziam os primeiros sinais da modernidade em Belo Horizonte." Carmona (2015) complementa esse pensamento e evidencia a ligação intrínseca com a poesia:

Contrários ou favoráveis, muitos dos escritores da época se debruçaram sobre a inovadora perspectiva de uma cidade nascida do papel. Poderíamos dizer que, desde o início, a vida de Belo Horizonte esteve ligada à literatura e, também, desde que nasceu, foi transformada em um campo de investigação poética, gerando temas para os poetas e promovendo, em seu território urbano, novos poetas que dela se alimentaram. (CARMONA, 2015, p. 21-22)

Nesse sentido é que se pode pensar que para além da escrita sobre a cidade, autores, poetas e poesia, passaram a atuar e influenciar a própria escrita e vivência da cidade. Carlos Drummond de Andrade, por exemplo, sob o pseudônimo de Antônio Crispim, escreveu uma série de crônicas sobre a capital das alterosas em que muitas vezes tratava de locais específicos. No belo horizonte afetivo de Drummond, a Rua dos Caetés, grande área comercial na época da fundação da cidade, era também "a rua mais camarada de todas: sempre disposta a fazer uma diferença, para você virar freguês" (DRUMMOND, 1984, p. 26). Já a Rua da Bahia, resumo arquitetônico, boêmio, literário e cultural, nos dizeres do poeta, era uma via feliz, e "tinha um ar de importância que irritava as outras ruas da cidade" (DRUMMOND, 1984, p. 39). Uma brincadeira de personificar lugares, que acabam por adquirirem rosto e proximidade num inconsciente coletivo. Como o escritor Roberto Drummond, em seu livro Hilda Furacão, ambientado na Belo Horizonte de 1950 a 1964, com algumas personagens, entidades e cenários reais e que oferece uma visão detalhada da Rua Guaicurus e da zona boêmia da cidade. A glamourização e figuras ilustres presentes no salão do dancing Montanhês ao longo das páginas, podem nem sempre corresponder à memória de quem frequentava o local, mas fizeram morada no imaginário dos belo-horizontinos.

É assim que uma única paisagem pode trazer inúmeras concepções. Marques (2015) acredita que $o$ ato de entender a cidade e suas dinâmicas a partir de diversos pontos de vista nunca tem fim. "Descobrir na cidade os rastros deixados pelos escritores, e descobri-la - a cidade de Belo Horizonte para compreendê-la, talvez, eis aí um desafio que diz respeito tanto ao transeunte a pé no corpo da cidade quanto ao escritor no seu espaço íntimo. Essa procura nunca tem fim.” (MARQUES, 2015, p. 36). Afinal, a cidade é isso: um compilado de história e poesia. 


\subsection{Cidade e design: palco de memórias}

Sobre as mesas de frio mármore, poemas foram lançados, retratos e caricaturas enfeitaram a noite, discussões filosóficas e políticas esquentaram a temperatura dos jovens que ainda não sonhavam com o tempo perdido. Era ali, no Café Estrela, que se reuniam à noite, Carlos Drummond de Andrade, Emilio Moura, Abgar Renault, Milton Campos, João Guimarães Alves, Pedro Nava, João Alphonsus, Aníbal Machado, a fina flor da inteligência belo-horizontina, pondo em irreverente polvorosa os alicerces de uma retrógrada estrutura social. (SALLES, 2005, p. 11)

Para compreendermos a relação entre o Design e a Memória dentro da cidade, é preciso entendermos a miscelânea entre história, arquitetura e sujeitos. Esses três pontos se inter-relacionam em uma conexão de troca constante. A memória vem logo em seguida e conecta todos esses itens.

A cidade não tem barreiras físicas, ela vai além, Cunha (2008) afirma que ela também é feita de vida e inter-relações. A vida coletiva em territórios é caracterizada por uma identidade cultural que se configura como um organismo vivo, em um processo dinâmico e incessante de reorganização, de relações sociais alicerçadas em patrimônios simbólicos transmitidos. As constantes transformações urbanas nas grandes cidades criam cenários que vão interferir de forma direta na vivência das pessoas e na formação da cidadania. "Nos espaços públicos, semipúblicos e privados se estabelecem as relações de participação social, política e é onde a vida local representa o seu papel cotidiano" (QUINAUD, 2018, p. 7).

As memórias da cidade são essências para a formação de sua identidade. Abreu (1998) acredita que seja importante registrar as memórias do presente para que as gerações futuras possam entender sua identidade:

[...] É através da recuperação das memórias coletivas que sobraram do passado (estejam elas materializadas no espaço ou em documentos) e da preocupação constante em registrar as memórias coletivas que ainda estão vivas no cotidiano atual da cidade (muitas das quais certamente fadadas ao desaparecimento) que poderemos resgatar muito do passado, eternizar o presente, e garantir às gerações futuras um lastro importante para a sua identidade. (ABREU, 1998, p. 27 e 28)

É interessante observar a existência da memória coletiva. Abreu (1998) presume que a memória coletiva surge uma vez que um mesmo grupo de indivíduos estabeleceu relações sociais em um mesmo lugar/ cenário. Portanto, uma única cidade possibilita que existam inúmeras memórias individuais, cada uma única, com um ponto em comum: a cidade.

Além da discussão entre história e memória, existe um termo que une ambos: patrimônio. $\mathrm{O}$ termo passou por diversas modificações desde que foi concebido até chegar ao sentido que conhecemos hoje, de legado ou herança cultural que transmite reconhecimento a um grupo social. A Constituição Federal de 1988, Artigo 216, ampliou o conceito de patrimônio, antes estabelecido pelo Decreto-lei $\mathrm{n}^{\circ} 25$ de 30 de novembro de 1937, de "Patrimônio Histórico e Artístico" para "Patrimônio Cultural Brasileiro", o que representa a incorporação de outros tipos de bens culturais, como os de caráter imaterial. O IPHAN, uma instituição federal vinculada ao Ministério da Cultura, é responsável pela preservação e fiscalização de bens culturais brasileiros, que são de extrema importância para a reiteração de sua identidade e sentimento de pertencimento.

A palavra patrimônio é extremamente importante para a compreensão da relação entre design e memória, e pode representar o recorte de uma época, um momento simbólico para a história de um lugar (ou de algo), que evoque uma lembrança a respeito de um objeto de estudo. Neste sentido, percebe-se notável a relação entre o patrimônio e a história e pode-se dizer que "o elemento determinante que define o conceito de patrimônio é a sua capacidade de representar simbolicamente uma identidade" (SILVA, 2000, p. 219).

A arquitetura, um dos pilares das cidades, está intimamente relacionada ao patrimônio. Não há como desassociá-la da memória de um lugar ou de uma cidade. Ela permite vínculos de todos os tipos, além de se tornar um referencial histórico. Os estilos arquitetônicos marcam gerações, são referências das épocas. Rodrigues (2012) evidencia a importância da arquitetura histórica. "A arquitetura das 
primeiras décadas da cidade, pode-se dizer de outra cidade, deixou rastros no território urbano. Esses objetos arquitetônicos presentificam outras épocas e fazem parte da tessitura urbana" (RODRIGUES, 2012, p.184). Nas últimas décadas é possível ver um movimento de preocupação com a preservação do patrimônio cultural brasileiro. "O passado das cidades brasileiras está sendo revalorizado e a preservação/recuperação/restauração do que sobrou das paisagens urbanas anteriores é um objetivo que vem sendo perseguido por inúmeros agentes, destacando-se aí os governos municipais." (ABREU, 1998, p. 23). Assim, se tem desde os primeiros movimentos de urbanização na cidade das alterosas, o design, mesmo que sem nome ou tratados específicos, como uma premissa a pontuar escolhas e decisões.

O designer, em sua atuação interdisciplinar, deve fazer a conexão entre a cidade e as pessoas que nela vivem, para que a memória dos lugares não deixe de existir e reflita sua identidade, pois uma cidade sem identidade é uma cidade que não consegue se expressar.Tendo em foco o fortalecimento do sentimento de apropriação da comunidade em relação à cidade onde habita, é de grande relevância a preservação de uma memória coletiva, que distingue o contexto de uma cidade.

O designer, ciente de como os processos cognitivos vinculados à memória se desenrolam na mente humana, pode articular vários elementos do sistema de forma a conduzir os indivíduos para uma melhor retenção dos eventos desencadeados nos sistemas com o intuito de fortalecer as relações entre o indivíduo com o objeto interativo. (NOJIMOTO, 2009. P. 103 e 104)

A experiência do usuário pode, também, estar atrelada ao design emocional, evocando sentimentos para tornar a experiência mais expressiva. Rosa (2009) chama atenção para o fato de cada sujeito humano possuir suas próprias particularidades como pessoas, com isso, cada produto deve atentar-se ao caráter afetivo que pode atingir através da semiótica.

Todos os discursos identificados com o Design \& Emoção apontam numa só direção: o respeito do sujeito humano, suas idiossincrasias, cultura, identidade, preferências, desejos e necessidades. E enfatizam a importância de o produto - via design - conter potencial afetivo (atributos que traduzam conceitos apropriados à cultura), capaz de se relacionar com o usuário através da simbolização. (ROSA, 2009, p. 77)

No contexto de uma cidade, o Design Emocional, que faz com que floresçam boas sensações para os usuários a partir dos sentimentos percebidos pelo contato inicial, expressa-se através da relação ser humano - cidade. Inúmeros elementos contêm potencial afetivo, como edifícios, praças, ruas, bairros, equipamentos urbanos, etc. Enfim, a cidade tem diversos pontos que se relacionam com os sujeitos e laços emocionais. O design de ambientes ao potencializar aspectos e dar significado ao espaço, alçando-o à condição de lugar, aponta valores, amplia o olhar e pode moldar o pertencimento.

\subsection{A linguagem poética na cidade}

"A relação com o mundo muda, o cotidiano automatizado dá lugar a individualidades e a linguagem torna-se veículo da manifestação do ser, da criação íntima, única, exclusiva de cada poeta." (PORTO, 2011, p. 62). A conexão com a cidade é algo particular e singular, cada um conecta-se de um modo e em um nível, desenvolvendo uma visão a compartilhar. Segundo Porto (2011), a poesia emerge do cotidiano, da sobrevivência, sentimentos e críticas, sob, ainda, influência da cultura, das relações interpessoais, da educação e da poesia.

A linguagem expressa individualmente na cidade tem força e cada pensamento importa. Afinal, o discurso urbano só pode ser construído a partir de retalhos de pensamentos individuais. Segundo Heidegger (2010), a própria linguagem é poesia, em seu sentido essencial. A linguagem é carregada de significados e, por isso, permite colher mensagens importantes sobre a vida das pessoas, inclusive torna possível ter interpretações político-sociais, o que é um potencial indicativo urbano. Porto (2011) destaca que a linguagem se tornou um instrumento de resistência social e afirmação de minorias. 
A linguagem, instrumento de comunicação e relacionamento, virou instrumento de resistência, afirmação de minorias, transformação política, revolução de costumes e resgate de significados comunitários. Além disso, uma nova literatura é desenhada e as manifestações poéticas, concentradas nos saraus, são como as pontas de muitos compassos, riscando outras centralidades. (PORTO, 2011, p. 61)

Seguindo uma linha cronológica da literatura e poesia em Belo Horizonte, logo após o início da vida literária, causado pela inauguração da cidade, houve uma agitação causada pela Semana de Arte Moderna de 1922. A agitação não chegou à cidade de início, uma vez que os jornais locais pouco veicularam sobre o evento. Porém, dois anos depois, em 1924, chegou à cidade a Caravana Paulista, que acabou por estreitar a relação entre os dois estados. Carmona $(2015$, p. 25$)$ destaca "A amizade aberta com os paulistas, principalmente entre Drummond e Mário de Andrade, fornece o sopro para acender as labaredas da irreverência mineira no cenário cultural de sua nova capital." Após a visita dos paulistas, foi publicada A Revista, no ano seguinte. A publicação, com apenas três números, foi o suficiente para fazer a literatura modernista mineira ser mais reconhecida.

Mário de Andrade escreve os versos de "Noturno de Belo Horizonte", que demonstram o impacto causado pela viagem à cidade:

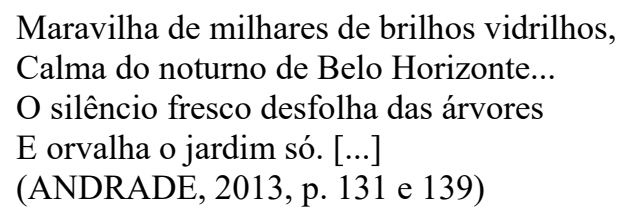

Pedro Nava, em seu livro Beira-Mar, registra detalhadas percepções da cidade de Belo Horizonte e seus encontros com outros escritores da época. Cardoso (2015) destaca o apreço do autor Pedro Nava pelos detalhes na escrita do livro, e observa o envolvimento afetivo de Pedro àquele tempo e lugar.

As lembranças de Pedro Nava captam, dessa forma, o cenário de Belo Horizonte e, ao serem narradas, desempenham sua função social. Portadora da memória, a paisagem trabalha como um mecanismo de construção de sentimentos e pertencimentos. Sua atmosfera está ligada a momentos da vida, tais como festas, reuniões, trabalho, perdas, ilusões, amores e desamores, encontros e desencontros. Enfim, a tudo aquilo que pertence ao espaço urbano. (CARDOSO, 2015, p. 19)

Cardoso (2015) observa também que é impossível separar o cenário material do imaterial, e disserta sobre o fato de cada indivíduo ter sua própria perspectiva.

A imagem ambiental captada pela memória é compreensível por sua identidade, estrutura e significado, em que a representação espacial do indivíduo assume uma forma própria, que entra em consenso com as captadas pelo grupo, por ser um lugar habitual a muitas pessoas. (CARDOSO, 2015, p.18)

Essa memória afetiva coletiva e individual também varia em tempo, espaço, maturidade ou distanciamento de um ponto. Em seu livro O Desatino da Rapaziada, Werneck (2012) fala da relação entre poetas e os arcos do Viaduto de Santa Tereza, uma das principais referências urbanas da cidade de Belo Horizonte. Lembra que a sua altura variava na memória dos que foram moços na época e andaram por eles, no ritual de passagem das gerações literárias de Minas. Segundo consta, para o já citado Pedro Nava, eles tinham uma altura vertiginosa, enquanto Fernando Sabino estimava 50 metros na primeira edição de Encontro Marcado e reduziu para 30, na segunda. Seus reais 14 metros de altura, no ponto mais ao nível do trilho, já haviam sido palco para as travessuras de Carlos Drummond de Andrade e a sua turma.

É assim que a identidade de um lugar engloba a linguagem de cada ser que nele habita, sob um olhar e em um determinado momento. Este sentido se potencializa com a capacidade do designer de 
criar sinergia entre os lugares e os sujeitos que dele usufruem. O design não é somente estilo ou adição externa de um toque estético, para além, realça a experiência física e funcional. É nesse ponto que o entendimento estratégico, presente na base da formação do designer, imprime um diferencial ao planejamento do espaço. Cada cidade permite uma pluralidade de intervenções, apropriações, pensamentos e com esse entendimento múltiplo acerca da significação de um lugar, é possível perceber de maneira mais abrangente como surgiram inúmeras outras formas de se falar, fazer poesia. Em Belo Horizonte os bares historicamente respiram poesia em forma de saraus, intervenções, manifestos, livros. Desde os famosos "cafés da Rua da Bahia" do início da cidade, misto de bar, confeitaria, mercearia e livraria. Frequentados por pensadores, poetas, jornalistas, políticos, artistas e intelectuais no início do século passado, há que se destacar o Bar do Ponto, Bar do Grande Hotel, Bar e Restaurante Colosso, Bar Trianon e a Gruta Metrópole, onde o mesmo Drummond e a mesma turma eram presença certa nas varandas em finais de tarde.

Hoje as despretensiosas "conversas de bar" e a cerimônia de encontrar os amigos em espaços como este são parte da cultura da capital mineira. Lugares de memória que se fazem uma deliciosa fonte de poesia urbana. Alguns bares de Belo Horizonte ficaram famosos pela vida boêmia que abrigam. Um exemplo, com quase 100 anos de história, é o Bar do Orlando, referência da boemia belo-horizontina, recebe o famoso Bloco dos Pescadores durante o carnaval e em outras ocasiões é palco da cena poética belo-horizontina. Abriga a Confraria dos Poetas, grupo que homenageia grandes escritores que moraram ou ainda vivem em $\mathrm{BH}$ e realiza uma série de intervenções pela cidade, como um muro em frente ao próprio do Bar do Orlando, nomeado "Muro dos Poetas", onde versos aparecem grafitados com a intenção de espalhar poesia pela cidade.

FIGURA 2 - Painel Edifício Garagem São José - dez. 2017

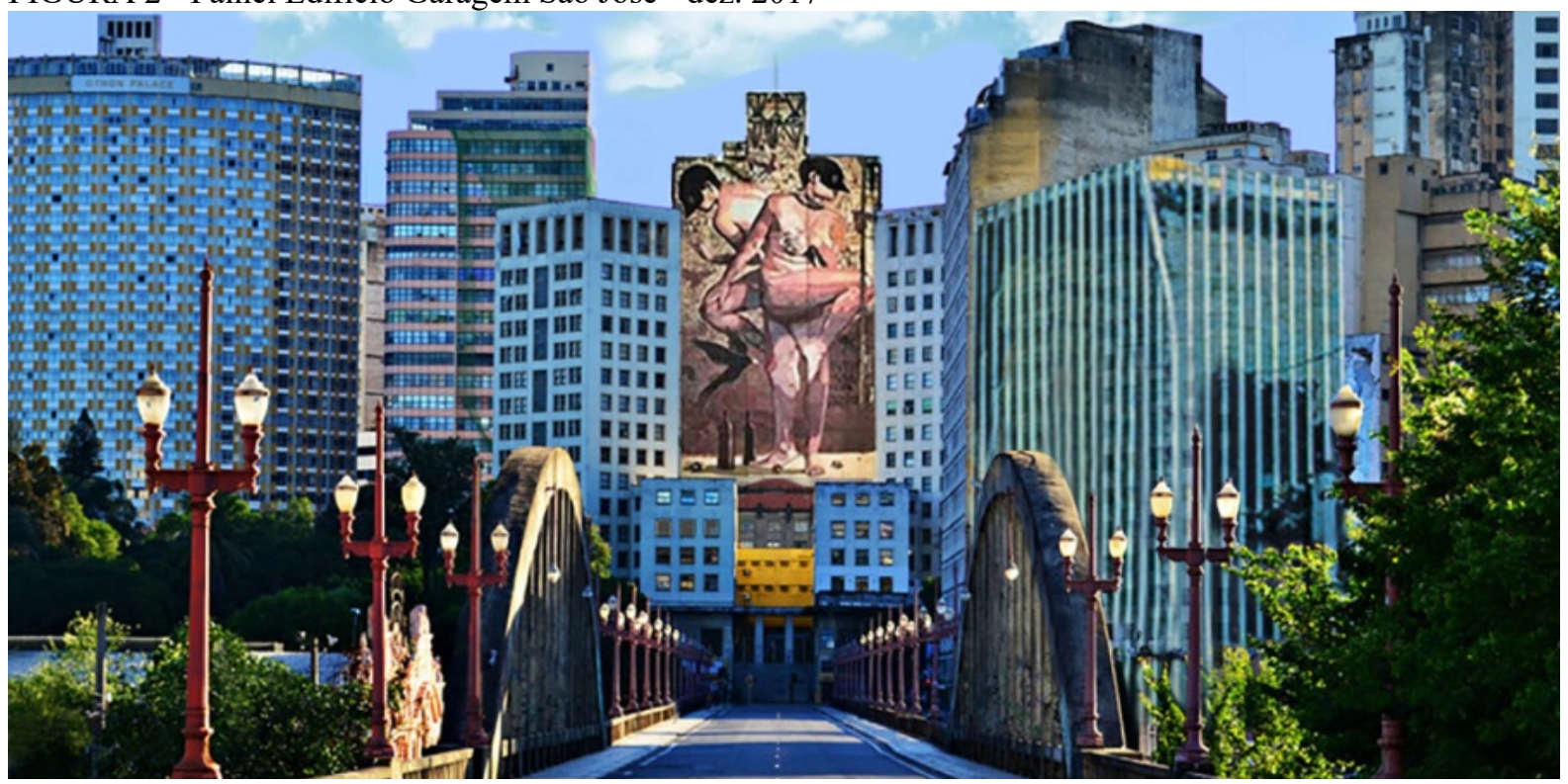

Fonte: Foto acervo pessoal.

Os grafites são, por sua vez, vistos aqui como uma forma de apropriação poética que colore as cidades, como pode ser visto na figura $2 \mathrm{em}$ painel do Coletivo Cura, localizado no centro da cidade de Belo Horizonte. Um tipo de linguagem, expressão de frases, desenhos, e afins, que tem sua essência descendente dos desenhos rupestres, quando o homem começou a sentir a necessidade de se expressar desenho, Teófilo et al (2011). Hoje em dia é natural caminharmos pela cidade e percebermos diversas manifestações desse cunho em muros. Blauth e Possa (2012) defendem que a natureza dos grafites é efêmera e é capaz de abordar diversos temas, como a crítica social, política e econômica, onde a presença da ironia ou humor é comum. Além disso, as autoras acreditam que a linguagem é acessível para um público transeunte ou sendo incorporada a espaços como galerias de arte. Desta forma, observa-se que os elementos urbanos viram telas em que é possível se expressar, registrando, portanto, uma identidade inerente à cidade. 
As paredes e os muros da cidade se tornam espaços culturais que vinculam identidades e adquirem uma função tanto social quanto artística no âmbito da denúncia social (SANTOS, 2010, p. 7).

Próximo ao grafite, configura-se ainda o picho e a poesia mural, que causam muita polêmica por uma estética não tão "palatável". Zan et al (2010) acreditam que a pichação, pelo fato de causar incomodo, aproxima-se da arte. Porém, os autores analisam também que há quem interprete a pichação como um instrumento polêmico de comunicação. Uma declaração ao direito de ir, vir, ficar, estar, se expressar. Na base da afirmação de todas as identidades no espaço público, e no espaço público urbano de uma maneira potencializada, é nesse momento que a conformação física das cidades, dentro das premissas do design, que mostra-se como um meio de incluir pessoas.

A poesia mural pode ser identificada dentro da poesia marginal, linguagem surgida na década de 1970. Essa tipologia trouxe possibilidades de atualização para a linguagem poética. Eble e Lamar (2015) acreditam que a literatura marginal retrata o social e carregam fortes questionamentos advindos da classe social que ela representa. Inclusive, ela se contrapõe à literatura elitizada e dominante, uma vez que é carregada de coloquialismos e temas relacionados ao universo da periferia. "[...] até, na nomenclatura, se denomina marginal pelo fato de ser representada por escritores e a temas à margem da sociedade." (EBLE; LAMAR, 2015, p. 205). A cidade planejada é sempre reformulada para poder abraçar todos que, desigualmente, nela vivem e interagem, fazendo jus às sua próprias formas de apropriação.

Outra vertente poética alinhada à poesia marginal são os 'slams de poesia'. Esse tipo pode ser resumido a disputas de poesia falada. Belo Horizonte possui uma cena cultural extremamente movimentada. A cidade, como tudo no mundo, permite linguagens muito diferentes, e a poesia marginal e a urbana são manifestações imensamente significativas. Como peças em um quebracabeças, as linguagens da cidade traduzem sua própria essência e suas possíveis modificações. Portanto, toda expressão é válida.

Slams, saraus poéticos, batalhas de rap, grafites, pichações, fotografias, músicas, etc. É interessante observar que não existe mais nenhum movimento poético que se destaque dos outros devido à sua força, mas, em contraponto, observam-se diversos focos espalhados pela cidade. A figura 3 apresenta algumas ações que acontecem sob o Viaduto de Santa Teresa, ponto de encontro icônico, cultural e de resistência na cidade de Belo Horizonte. Esses focos são os poetas, que escolhem uma (ou mais) formas de poesia para conversar com e sobre a sua relação com a cidade.

FIGURA 3 - Quarteirão do Soul, batalha de rap, slam de resistência sob o viaduto. Abril 2016.
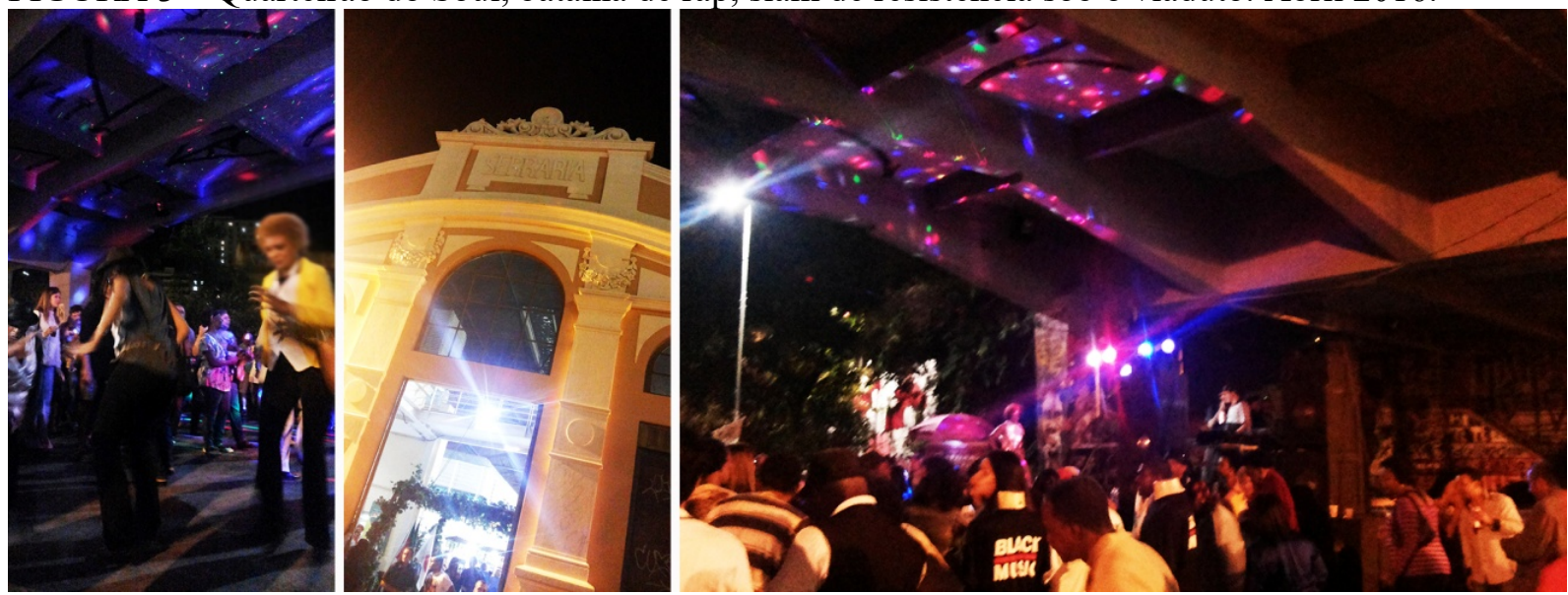

Fonte: Foto arquivo pessoal.

Belo Horizonte, através das gerações, sofreu mudanças gigantescas em sua configuração física, e isso sempre acabou por refletir nas pessoas que nela habitam. É muito interessante e extremamente significativo entender a relação das pessoas com a cidade e os reflexos literários que essa relação gera. E ainda perceber o design nesse processo como um construto de premissas e ações que levam em consideração os aspectos funcionais, ergonômicos e estéticos, bem como históricos, 
culturais, sociais, econômicos, na busca por um ambiente que expresse visualmente ideias, transmita identidade e preze pelo bem estar e pela qualidade de vida. Novas escritas que levam a novas leituras de cidade.

\section{Considerações finais em novos tempos}

Dentre os diversos olhares, relações e pertencimentos observados no cotidiano das cidades, se tem nas manifestações poéticas, artísticas e culturais de rua um meio significativo de interação e desnudamento das urgências. Nesse sentido é que se pode perceber Belo Horizonte, com todas as suas histórias e contextos, como uma cidade planejada para ser muitas coisas, mas que nem sempre abraça todos os seus sujeitos. Por outro lado, a conformação e produção contínua e até espontânea do espaço, ajuda a promover uma experiência complexa e intensa de cidade. Sua essência boêmia, nunca perdida, se materializa no espaço urbano que serve de palco para várias formas de poesia. Ao acolher um público diverso, com dissonâncias, confluências e tensões, reafirma sua vocação como cenário que concilia também o velho e o novo, o passado e o presente. É certo que a identidade de um lugar está ligada à sua memória, e a poesia, intrínseca nele, pode acrescentar vida. É aí que o design de ambientes se configura agente da viabilização do resgate da essência da cidade. E isso vale para toda coisa pública, seja um poste de iluminação com mais de cem anos, um abrigo de ônibus com foco tecnológico, uma empena de edifício grafitada ou uma frase inspiradora escrita em um muro. A cidade se conforma espacialmente se valendo de modos desiguais de apropriação, com desequilíbrio e uma delimitação de territórios bastante demarcada.

Ao perceber a poesia e Belo Horizonte como companheiras inseparáveis, se consegue construir uma percepção no sentido de que as escolhas projetuais de configuração dos espaços e a poesia sempre presente, impactam diretamente as formas de inclusão ou pertencimento. Muitas singularidades surgem nesse cenário em que se encontram as vocações espontâneas de uso dos lugares públicos, as tentativas de preservação da memória, as diretrizes e planejamentos propostos pelos projetos de design para espaços de coletividade e as intervenções poéticas. Uma vez que a identidade da cidade se relaciona à linguagem de todos os sujeitos que nela habitam, a acomodação desses impasses vai exigir um processo dialético constante entre os responsáveis pelas políticas de revitalização urbana, do patrimônio cultural, os designers e agentes promotores da configuração dos espaços, e os seus fruidores. A busca por estratégias que se desenvolvam com o objetivo de amplificar a conexão entre a cidade e as pessoas que nela vivem, própria do design, aponta um caminho possível. Em Belo Horizonte a força das trilhas poéticas e a tentativa de preservação de uma memória coletiva podem ser observadas e distinguem um contexto plural de cidade, onde mesmo com olhar triste ao descaso do poder público, Drummond se permitiu a ressalva: "Não, Mário, Belo Horizonte não era uma tolice como as outras." Por suas ruas caminha muita poesia.

No contexto atual, de mundo em pandemia, onde valores arraigados são postos à prova, urgências são relativas e certezas precisam ser revistas, de certo fica a arte... Que traz conforto e contraponto, esperança, respiro que às vezes literalmente falta, mas também faz pensar. Oferecer a esse novo tempo, que forçosamente tem que se reinventar, lugares de memória, convivência poética, apropriação e pertencimento, é um dos presumíveis ganhos ao se voltar o olhar sobre esses temas na busca das inter-relações possíveis entre eles. Sabendo que essas questões vão bem além dos limites desse texto, ficam as deixas, ponderações, provocações e o convite a outras e bem vindas discussões.

As coisas tangíveis tornam-se insensíveis à palma da mão.

Mas as coisas findas, muito mais que lindas, essas ficarão. 
Design, poetry and life: Memory and belonging in the city of Belo Horizonte

Abstract: Belo Horizonte is a historically cultural city, with an active nightlife, many bars and meetings and poets who recorded their essence in books and newspapers. The city has been a poet since it was born. Its scenarios - natural, urban and political - have always been the subject of sensitive and, at the same time, critical views. The aim of this work was to discuss the relationship between design, poetry and the city, addressing belonging as a key piece. Belo Horizonte's history, memory and relationship with poetry were studied through the interdisciplinary look of design. The diverse public of the city uses urban space in its own way, a great stage of memories, which design is responsible for rescuing and understanding. In this new current context, where ingrained concepts need to be revised, thinking about possible paths for art is also breathing. The methodology used was bibliographic research, in addition to direct observation of the object of study - the city.

Keywords: Belo Horizonte; design; memory; belonging; poetry

\section{Referências bibliográficas}

ABREU, Maurício Almeida. Sobre a Memória das Cidades. Revista Território, Rio de Janeiro, v. 4, p. 5-26, 1998. Disponível em: http://www.revistaterritorio.com.br/pdf/04_2_abreu.pdf. Acesso em: 01 mai. 2019.

ANDRADE, Mário de. Poesias completas. Rio de Janeiro: Nova Fronteira, v.1, 2013. 369p.

BARTHES, Roland. A aventura semiológica. Tradução Mário Laranjeira. - São Paulo: Martins Fontes, 2001.

BLAUTH, Lurdi; POSSA, Andrea. C. K. Arte, grafite e o espaço urbano. Palíndromo, Programa de Pós-Graduação em Artes Visuais, CEART/UDESC, 4(8). Florianópolis, 2012. Disponível em: < http://www.revistas.udesc.br/index.php/palindromo/article/view/3458>. Acesso em 26 mai. 2019.

CARDOSO, João E. D. Por entre ruas e memórias: a Belo Horizonte no beira-mar de Pedro Nava. 2015. 164 f. Dissertação (Mestrado em História) - Universidade Federal de Goiás, Goiânia, 2015. Disponível em <http://repositorio.bc.ufg.br/tede/handle/tede/5259>. Acesso em 12 mai. 2019.

CARMONA, Kaio Carvalho. 26 Poetas ontem. Belo Horizonte Literária. Tese (Doutorado em Literatura Brasileira) - Faculdade de Letras. Universidade Federal de Minas Gerais, 2015. Disponível em: <http://www.bibliotecadigital.ufmg.br/dspace/bitstream/handle/1843/ECAPA5BK5X/tese.pdf?sequ ence=1>. Acesso em 19 Mar. 2019.

CARMONA, Kaio Carvalho. Belo Horizonte literária: a cidade e a poesia. REVISTA OPINIÕES. REVISTA DOS ALUNOS DE LITERATURA BRASILEIRA USP, v. 5, p. 38-45, 2016. Disponível em: <www.revistas.usp.br/opiniaes/article/download/124614/121139/>. Acesso em 19 Mar. 2019.

CUNHA, Erika Jorge Rodrigues da. A natureza do espaço urbano: formação e transformação de territórios na cidade contemporânea. Belo Horizonte. Escola de Arquitetura da UFMG. Dissertação de Mestrado. Belo Horizonte, 10 de abril de 2008. Disponível em: < http://www.bibliotecadigital.ufmg.br/dspace/bitstream/handle/1843/RAAO7EFPDL/a_natureza_do_esp a_o_urbano.pdf?sequence=1>. Acesso em 01 mai. 2019.

DRUMMOND, Carlos Drummond de Andrade. Crônicas de Carlos Drummond de Andrade - sob o pseudônimo de Antônio Crispim. Revista do Arquivo Público Mineiro. Belo Horizonte, p. 9- 96, 1984.

EBLE, Taís A.; LAMAR, Adolfo R.. A literatura marginal/periférica: cultura híbrida, contra-hegemônica e a identidade cultural periférica. Especiaria: Cadernos de Ciências Humanas, Santa Cruz, v. 15, n. 27, 
p. 193-212, 2015. Disponível em: http://periodicos.uesc.br/index.php/especiaria/article/viewFile/1126/1005. Acesso em: 12 mai. 2019. HEIDEGGER, Martin. A origem da obra de arte; [tradução de Idalina Azevedo e Manuel Antônio de Castro]. - São Paulo: Edições 70, 2010.

IPHAN. Patrimônio cultural. Brasília: Instituto do Patrimônio Histórico e Artístico Nacional.

LEMOS, Celina Borges; GUERRA, Kátia Bilharinho (Org.). Casa nobre: significados dos modos de morar nas primeiras décadas de Belo Horizonte. Belo Horizonte: Frente Verso, 2019. 252p.

LEMOS, Celina Borges; ALBANO, M. C. P. Determinações do espaço urbano: a evolução econômica urbanística e simbólica do centro de Belo Horizonte. 1988. 2v., enc. Dissertação (mestrado) - Universidade Federal de Minas Gerais, Faculdade de Filosofia e Ciências Humanas. In: LEMOS, C. \& GUERRA, K. B. :LEMOS, Celina BORGES, C; GUERRA, K. B. (Org.). Casa nobre: significados dos modos de morar nas primeiras décadas de Belo Horizonte. Belo Horizonte: Frente Verso, 2019. 252p.

MACHADO, Valéria Aparecida de Souza. A cidade moderna: Belo Horizonte nas crônicas de Carlos Drummond de Andrade. Outra travessia, Florianópolis, n. 8, p. 77-89, dez. 2009. ISSN 2176-8552. Disponível em: <https://periodicos.ufsc.br/index.php/Outra/article/view/16251>. Acesso em: 20 mar. 2019.

MARQUES, Fabrício. Uma cidade se inventa: Belo Horizonte na visão de seus escritores; Ensaio fotográfico de João Marcos Rosa. Belo Horizonte: Editora Scriptum, 2015. 350p.

NOJIMOTO, Cynthia. Design para experiência: processos e sistemas digitais. Dissertação (Mestrado-Programa de Pós-Graduação em Arquitetura e Urbanismo na Área de Concentração em Teoria e História da Arquitetura e Urbanismo). Escola de Engenharia de São Carlos da Universidade de São Paulo, 2009. Disponível em:< http://www.teses.usp.br/teses/disponiveis/18/18142/tde10092009-154626/pt-br.php>. Acesso em 17 Mar. 2019.

PORTO, Gisele Poletto. Poéticas periféricas: outras centralidades? Ide (São Paulo) [online]. 2011, vol.34, n.53. Disponível em: <http://pepsic.bvsalud.org/scielo.php?script=sci_arttext\&pid= S010131062011000200007>. Acesso em 12 mai. 2019.

QUINAUD, Paula Márcia A. Design e atividade humana nos espaços de sociabilidade urbana: interações no Baixo Centro de Belo Horizonte. Estudos Design v. 26, n. 3, 2018. Disponível em: <https://estudosemdesign.emnuvens.com.br/design/article/view/645/353\#>. Acesso em 12 mai. 2019.

REIS, A. Ofício n. 26. Belo Horizonte, 23 mar. 1895. Apresentado ao governo as plantas da cidade. Belo Horizonte, 1895. Arquivo Público Mineiro. Acesso em 06 mai. 2019.

RODRIGUES, Rita Lages. Architecto Moderno na Cidade: Traços e rastros de Luiz Olivieri em Belo Horizonte. Tese (Doutorado) - Programa de Pós-Graduação em História da UFMG. Belo Horizonte, 2012. Disponível em: <http://www.bibliotecadigital.ufmg.br/dspace/handle/1843/BUOS-

9A3JM6?show=full>. Acesso em 11 mai. 2019.

ROSA, Velcy Soutier. Design e Emoção: A mediação do designer na interpretação dos desejos e necessidade das pessoas. 107p. Dissertação (Mestrado em Design), Escola de Engenharia e Faculdade de Arquitetura, Universidade Federal do Rio Grande do Sul, Porto Alegre, RS, 2009. Disponível em: < https://lume.ufrgs.br/handle/10183/17628>. Acesso em 18 Mar. 2019.

SALLES, José Bento Teixeira de. Rua da Bahia. Coleção BH: a cidade de cada um, volume 4 (Rua da Bahia). Belo Horizonte: Conceito Editorial, 2005. 87p.

SANTOS, Roberto. E.; FIALHO, Thiago. A. Cadernetas de Campo da Comissão Construtora da Nova Capital. Preservação Digital e Horizontes de Estudo. 2016.

SANTOS, Thaís Maria dos. Grafite: a leitura dos muros. VI ENECULT, Encontro de Estudos Multidisciplinares em Cultura. (Facom-UFBa), 25-27 de maio, 2010, Salvador-BA. Disponível em: <http://www.cult.ufba.br/wordpress/24406.pdf>. Acesso em 26 Mai. 2019. 
SILVA, Elsa Peralta da. Patrimônio e Identidade: Os desafios do turismo cultural. Revista Antropológicas n.4, Lisboa: Universidade Técnica de Lisboa, 2000. Disponível em: https://revistas.rcaap.pt/antropologicas/article/view/932. Acesso em: 09 Mai. 2019

TEÓFILO, Ana Bárbara S.; PEREIRA, Mirna Feitosa; LOPES, Valter Frank M. Grafite como

linguagem: apontamentos teóricos e metodológicos de estudo sobre as interferências do espaço da cidade na manifestação do grafite. X Congresso de Ciências da Comunicação na Região Norte - Boa Vista - RR - 1 a 3 de junho, 2011. Disponível em:

<http://intercom.org.br/papers/regionais/norte2011/resumos/R26-0305-1.pdf> Acesso em 26 Mai. 2019.

WERNECK, Humberto. 0 desafio da rapaziada - Jornalistas e Escritores em Minas Gerais. São Paulo: Companhia das Letras, 2012.

ZAN, Dirce; BATISTA, Elise; CAMPOS, Maria Teresa de Arruda; RAGGI, Nathália; LIMA, Tatiana. Grafite e pichação: formas de resistência e participação juvenis. Educação (UFSM), Santa Maria, p. 465 - 478, dez. 2010. ISSN 1984-6444. Disponível em:

<https://periodicos.ufsm.br/reveducacao/article/view/2356>. Acesso em: 02 jun. 2019. 